\title{
Avaliação de dor utilizando a escala Grimace e termografia ocular em cavalos Puro Sangue Inglês de corrida com e sem afecções ortopédicas
}

Fernanda CM Barussi, Fernanda Z Bastos, Tâmara D Borges, Bianca P Vieira, Pedro V Michelotto Jr

Pontifícia Universidade Católica do Paraná (PUCPR), Curitiba, PR, Brasil

*Autor correspondente

e-mail: michelottojunior@yahoo.com.br

\section{Resumo}

A termografia ocular (TO) foi demonstrada como uma das técnicas mais sensíveis para detecção do estresse. A carúncula lacrimal é amplamente irrigada e estimulada pelo sistema simpático, assim, sua resposta ao estresse tende à vasodilatação local e aumento da temperatura. A escala facial de dor (EFD) é uma avaliação baseada em escores que classificam a condição dolorosa dos equinos a partir da expressão facial dos próprios animais. 0 objetivo do presente estudo foi avaliar a aplicabilidade da TO e da EFD na avaliação de dor em cavalos Puro Sangue Inglês (PSI) de corrida jovens com e sem afecção ortopédica. Cavalos PSI de corrida jovens foram divididos em dois grupos - animais com sinais clínicos ortopédicos (CS, n = 7) e animais saudáveis e sem sinais clínicos ortopédicos (SS, $\mathrm{n}=7$ ) -, fotografados para mensuração da EFD (ausente-0, moderada-1 e óbvia-2 em orelhas, olhos, área ao redor dos olhos, músculos faciais, região bucal e narinas) e avaliados através da TO a fim de monitorar a temperatura da glândula lacrimal. Para a TO utilizou-se câmera térmica FlirE50bx (a 0,5m do olho) e a EFD foi avaliada por imagem digital obtida no mesmo momento da T0, realizada por avaliador alheio às demais informações. Para a TO, analisou-se a média entre os maiores valores encontrados em ambos os olhos para a temperatura da glândula lacrimal. A análise estatística foi feita pelos testes de Kuskal-Wallis e correlação de Spearman considerando $\mathrm{P}<0,05$. O estudo foi aprovado pelo CEUA da PUCPR (registro 0951A). Os valores obtidos na TO não apresentaram diferença entre os grupos (média de $36,85^{\circ} \mathrm{C}$ para SS e 36,58ㅜㅡ para CS), mas animais em condição de dor óbvia, no grupo CS, apresentaram diminuição na temperatura da glândula lacrimal em relação aos demais $(\mathrm{P}=0,044)$. 0 grupo SS manteve EFD em 0 e o CS variou entre 1 e 2 , com diferença entre eles $(P=0,0006)$, sendo que três indicadores (área ao redor dos olhos, músculos faciais e região bucal) foram determinantes para esta avaliação em todos os animais. Há alteração da perfusão sanguínea na região da glândula lacrimal após condição de dor severa, necessitando de mais estudos. A EFD, embora subjetiva, é uma técnica eficaz 
para o monitoramento de dor em equinos. Maior número de equinos e avaliação dinâmica (filmagem/ registro de mais momentos) forneceriam respostas mais conclusivas.

Palavras-chave: Bem-estar. Equinos. Estresse. 